\title{
Study of the Role of Ultrasonography to Differentiate between Benign and Malignant Thyroid Nodules and its Correlation with Fine Needle Aspiration Cytology in a Teaching Hospital
}

\author{
Kalyan Sekhar Popuru ${ }^{1}$ \\ ${ }^{1}$ Assistant Professor, Department of Radiology, Mamata Academy of Medical Sciences, Bachupally, Telangana, India.
}

Corresponding author: Dr. Kalyan Sekhar Popuru, Assistant Professor, Department of Radiology, Mamata Academy of Medical Sciences, Bachupally, Telangana, India.

DOI: http://dx.doi.org/10.21276/ijcmsr.2020.5.1.9

BY-NC-ND

How to cite this article: Kalyan Sekhar Popuru. Study of the role of ultrasonography to differentiate between benign and malignant thyroid nodules and its correlation with fine needle aspiration cytology in a teaching hospital. . International Journal of Contemporary Medicine Surgery and Radiology. 2020;5(1):A39-A42.

\section{A B S T R A C T}

Introduction: Thyroid nodule is a common clinical finding. In the past two decades, the widespread use of ultrasonography for evaluation of thyroid and non-thyroid neck diseases has increased the detection rate and prevalence of thyroid nodules. It is widely accepted that Sonography and ultrasound guided FNA Cytology are the modalities of choice for comparison of benign and malignant nodules. Current research aimed to study the role of Ultrasonography to differentiate benign and malignant thyroid nodules in correlation with Fine-Needle Aspiration Cytology in a teaching hospital.

Material and Methods: This was a prospective hospital based study, done over a period of one year. A total of 120 cases were studied. USG examination of thyroid was done for all the patients presenting with anterior neck swellings and /or thyroid nodules followed by FNAC.

Results: The patient age ranged from 10 to 75 years and the male to female ratio was $1: 2$. On ultrasound neck 120 were reported as benign, 10 (8.57\%) were reported as malignant. On cytopathology a total of 115 cases (95.8\%) were diagnosed as benign lesions and 05 (4.1\%) were reported as malignancy.

Conclusion: Lesions of the thyroid are common in the general population and middle-aged females are more often affected than males. Benign lesions outnumber the malignant lesions. Well defined margins, predominantly solid texture, absence of microcalcification, hyperechoiec and isoechoiec lesions, wider-than-taller lesions and presence of peripheral halo are pointers towards benign pathology. USG findings of thyroid correlate well with the cytopathological diagnosis.

Keywords: USG of Thyroid, FNAC of Thyroid, Calcifications in Thyroid

\section{INTRODUCTION}

Thyroid nodule is a common clinical finding and on autopsy examination it is found, in aproximately $50 \%$ of individuals. ${ }^{1}$ Based on clinical examination, its prevalence is about four to seven percent. ${ }^{2,3}$ In the past two decades, the widespread use of ultrasonography for evaluation of thyroid and non-thyroid neck diseases has increased the prevalence of thyroid nodules and the prevalence rate has varied among different studies. ${ }^{4-6}$ Thyroid fine-needle aspiration cytology (FNAC) was introduced in 1950 and became popular over the past 40 years since $1980 .^{7}$ Today, it is a well-established technique for preoperative diagnosis of thyroid pathologies. Thyroid lesions cause various signs and symptoms and also have malignant potential. ${ }^{8}$ FNAC is considered to be the "gold standard" in the selection of patients for surgery. ${ }^{9}$

It is widely accepted that Sonography and ultrasound guided FNA Cytology are the modalities of choice for comparison of benign and malignant nodules. ${ }^{10,11}$

Ultrasound was first used to study the thyroid gland in 1967, primarily to distinguish solid lesions from cystic lesions. ${ }^{12}$
Nodular thyroid disease is detected in $3-7 \%$ of the adult population worldwide. They are common in females with a ratio of 5:1 and prevalence mainly depends on the age, gender, iodine intake, diet (goitrogens), therapeutic and environmental exposure. The majority of these cases are clinically occult but readily detected by high-resolution ultrasonography (USG). ${ }^{13,14}$

Thyroid sonography was first introduced in 1966-1967. ${ }^{6}$ It has been widely practiced since the 1970 and is now one of the most popular radiological methods of diagnosing thyroid disease..$^{15}$

Fine needle aspiration cytology (FNAC) is now a wellestablished, first line, simple and quick screening test as well as the diagnostic tool for surgical and non-surgical goitres. Limitation of FNAC is mainly because of inadequate sampling, inexperience of the pathologist and over-lapping cytological features. ${ }^{16}$

Current research aimed to study the role of Ultrasonography to differentiate benign and malignant thyroid nodules in correlation with Fine-Needle Aspiration Cytology in a teaching hospital. 


\section{MATERIAL AND METHODS}

This was a prospective hospital based study, done in the department of Radiodiagnosis at Mamata Academy of Medical Sciences, Bachupally, Hyderabad, Telangana. No ethical issues were involved. Informed consent was taken from all patients posted for ultrasound (USG) study and FNAC.

The study was done over a period of one year from July 2018 to June 2019. A total of 120 cases were studied. Patients presenting with anterior neck swellings and /or as thyroid nodules were referred from the departments of General Surgery, ENT and General Medicine were referred for ultrasound examination of the neck. All the patients were evaluated by thorough clinical examination. Routine investigations such as haemogram, renal function tests, liver function tests and thyroid function tests advised by the respective departments. Ultrasound of neck was done in our department in all cases using high-frequency linear array Ultrasound transducer.

Equipment: In the present study, gray-scale real-time ultrasound examination was done using 7.5 MHz linear array transducer. Ultrasound machines used were SONOSCAPE S6.

Technique of Examination: The patient was examined in the supine position with an extended neck. A pillow was placed under the shoulders to provide better exposure of the neck. Since the gland is situated superficially, 7.5 MHz linear array transducer was used.

The entire thyroid gland from upper to the lower pole and the isthmus was examined in the longitudinal and transverse planes. Bilateral carotid arteries, jugular veins, and supraclavicular fossa were also examined. These cases were subjected to FNAC for confirmation of ultrasound findings and establishment of diagnosis. FNAC thyroid was done in all 120 cases under aseptic precautions. FNAC was performed with $23 \mathrm{G}$ needle, smears were fixed with isopropyl alcohol and stained with Hematoxylin and Eosin stains (H\&E). USG and cytology results were correlated and analyzed.

\section{Inclusion Criteria:}

1. Age group from 10 years to 75 years

2. Both genders

3. All the patients with thyroid nodule detected on ultrasound

4. All patients with thyroid nodules suspicious of malignancy, irrespective of its size.

\section{Exclusion Criteria:}

1. Age group less than10 years

2. All patients with diffuse thyroid enlargement were excluded

\section{RESULTS}

In the present study a total of 120 patients were included. On ultrasound neck of the 120 thyroid cases examined, 120 were reported as benign, 10 (8.57\%) were reported as malignant. On cytopathology a total of 115 cases $(95.8 \%)$ were diagnosed as benign lesions and 05 (4.1\%) were reported as malignancy. In the present study, age group distribution included from

\begin{tabular}{|l|c|c|}
\hline Age distribution (in years) & No. of cases & Percent (\%) \\
\hline $10-14$ & 05 & $4.1 \%$ \\
\hline $15-29$ & 20 & $16.6 \%$ \\
\hline $30-44$ & 83 & $69.1 \%$ \\
\hline $45-59$ & 10 & $8.3 \%$ \\
\hline $60-74$ & 02 & $1.6 \%$ \\
\hline Total & 120 & $100 \%$ \\
\hline \multicolumn{2}{|c|}{ Table-1: Age-wise distribution of the cases } \\
\hline
\end{tabular}

\begin{tabular}{|l|c|c|}
\hline Gender & No. of cases & Percent (\%) \\
\hline Females & 80 & $66.6 \%$ \\
\hline Males & 40 & $33.3 \%$ \\
\hline Total & 120 & $100 \%$ \\
\hline \multicolumn{2}{|c|}{ Table-2: Gender-wise distribution of the cases } \\
\hline
\end{tabular}

\begin{tabular}{|l|c|c|}
\hline USG findings & Benign & Malignant \\
\hline Margins & & 4 \\
\hline Well defined & 100 & 8 \\
\hline Poorly defined & 10 & \\
\hline Internal composition & & 12 \\
\hline Solid & 100 & 16 \\
\hline Cystic & 6 & 0 \\
\hline Honey comb & 6 & \\
\hline Calcification & & 8 \\
\hline Present & 20 & 4 \\
\hline Absent & 110 & 0 \\
\hline Echogenicity & & 4 \\
\hline Hyperechoeic & 46 & 0 \\
\hline Hypoechoeic & 52 & 6 \\
\hline Isoechoic & 18 & 6 \\
\hline Shape & 8 & \\
\hline Taller than wider & 120 & 10 \\
\hline Non taller than wider & & \\
\hline Peripheral halo & 110 & \\
\hline Present & 10 & \\
\hline Absent & & \\
\hline \multicolumn{2}{|c|}{ Table-3: Ultrasound findings of the cases } \\
\hline
\end{tabular}

\begin{tabular}{|l|c|c|}
\hline Microscopy diagnosis & No. of cases & Percent (\%) \\
\hline Nodular goitre & 59 & $49.1 \%$ \\
\hline Colloid goitre & 12 & $10 \%$ \\
\hline Colloid nodule & 15 & $12.5 \%$ \\
\hline Follicular neoplasm & 11 & $9.1 \%$ \\
\hline Hashimoto's thyroiditis & 17 & $14.1 \%$ \\
\hline Acute suppurative thyroiditis & 01 & $0.8 \%$ \\
\hline Suggestive of malignancy & 05 & $4.1 \%$ \\
\hline Total & 120 & $100 \%$ \\
\hline \multicolumn{2}{|c|}{ Table-4: Cytopathology - FNAC diagnosis of the cases } \\
\hline
\end{tabular}

\begin{tabular}{|l|c|c|}
\hline & USG & FNAC \\
\hline Benign & 110 & 115 \\
\hline Malignant & 10 & 05 \\
\hline Total & 120 & 120 \\
\hline \multicolumn{2}{|c|}{ Table-5: Comparison between USG findings and FNAC } \\
\hline
\end{tabular}


10 years to 75 years. Majority of the patients, ie $50 \%$ were among 30-44 years (table-1).

In the present study, majority of the patients were females $66.6 \%(80 / 120)$ compared to males $33.3(40 / 120)$ and the male to female ratio was 1:2 (table-2).

Clinical features: In the present study most of the cases (80/120, 66.6\%) presented as solitary nodule and 40/120, $33.3 \%$ cases presented as multiple nodules.

Most of the benign nodules were well defined with thin peripheral continuous halo. All the nodules with peripheral eggshell calcifications were benign. Most of the benign nodules were predominantly solid; however, all the cystic lesions were benign. All the hyperechoic and isoechoic nodules were benign. Most of the malignant nodules were ill defined with shape taller than wider. Microcalcifications were seen in both benign and malignant cases. All malignant nodules were profoundly hypoechoic with the absence of well-defined peripheral halo. All malignant nodules were predominantly solid (table-3).

In the present study, on cytology a total of 115 cases $(95.8 \%)$ were diagnosed as benign lesions and 05 (4.1\%) were reported as malignancy (table-4,5).

\section{DISCUSSION}

Sample size: In the present study a total of 120 patients were included. On ultrasound neck, out of the 120 thyroid cases examined, 110 were reported as benign and 10 (8.57\%) were reported as malignant.

Sharma et $\mathrm{al}^{17}$ in their study of 138 thyroid nodules found 124 to be benign and 14 to be malignant. Kim et al ${ }^{18}$ studied 201 sponge-like nodules, and found 196 were benign (14 confirmed by surgery, 182 confirmed by repeated cytology) and five were malignant nodules, as confirmed by surgery.

Age distribution: In the present study, majority were among 30 to 45 years ie, $50 \%(83 / 120)$ and the next common age group was among $15-30$ years ie, $16.6 \%$ (20/120) cases.

In a study by Bairi et $\mathrm{al}^{19}$ the youngest patient was 16 years of age and oldest 70 years. The maximum number of cases was seen in the age group of 31-40 years (41\%) and 41-50 years $(25.7 \%)$.

Gender distribution: in the present study, majority of the patients were females, $66.6 \%(80 / 120)$ compared to males 33.3 (40/120). Sharma et $\mathrm{al}^{17}$ also in their study observed a definite female preponderance with 118 females and 20 males with range of females and males being 18 to 67 years and 26 to 72 years respectively.

Bairi et $\mathrm{al}^{19}$ also reported a definite female preponderance with $81.4 \%$ females and $18.5 \%$ males.

Chinta et $\mathrm{al}^{20}$ also observed thyroid lesions to be more common in women. In their study of 100 cases, 89 were women and 11 were men.

In the study by Banstola et $\mathrm{al}^{21}$ female patients outnumbered male patients by a ratio of 9: 1 . Our findings compare well with the above studies.

Ultrasonography findings: In the present study, all the malignant nodules were profoundly hypoechoic with the absence of well-defined peripheral halo. All the malignant nodules were predominantly solid. This correlates well with the observations of Bairi et $\mathrm{al}^{19}$ and Sharma et $\mathrm{al}^{17}$ studies.

In the study by Sharma et $\mathrm{al}^{17}$ Ultrasonography was able to correctly identify 10 out of 14 malignancies, and 118 out of 124 benign nodules. Ten nodules were described as suspicious for malignancy on USG; final pathologic diagnosis was malignancy in 2 cases, benign follicular nodule in 7 cases and focal thyroiditis in 1 case.

Chinta et $\mathrm{al}^{20}$ studied 100 lesions with high resolution USG (HRUSG) and observed 70 lesions (65 benign, 5 malignant) as well defined lesions which were then diagnosed on FNAC. 30 lesions (20 malignant, 10 benign) were ill defined on HRUSG. If ill-defined borders of the lesion were considered as an independent factor indicative of malignancy, then HRUSG could detect a malignant lesion with sensitivity, specificity, positive and negative predictive value of $80 \%$, $87 \%, 67 \%$ and $93 \%$ respectively.

Calcifications: In our study, microcalcifications were seen in 20 cases in benign and in 8 cases in malignant nodules. Sharma et $\mathrm{a}^{17}$ reported the calcifications as either microcalcification or macrocalcification. Microcalcifications were seen exclusively in papillary carcinomas occurring in $8 / 9$ cases. Macrocalcifications were seen in 5/14 malignancies and in 28/124 benign nodules.

Kim et $\mathrm{al}^{18}$ observed calcifications in only 11 nodules; microcalcifications were found in five nodules, macrocalcifications in one nodule, both microcalcifications and macrocalcifications in one nodule, and rim calcification in four nodules.

Bairi et $\mathrm{al}^{19}$ have proposed that microcalcifications have the highest accuracy in diagnosing malignant thyroid nodules followed by taller-than-wide shape, ill-defined margins, marked hypoechogenicity, and absent peripheral halo.

Benign: In the present study most of the benign lesions were well-defined with thin peripheral halo on USG. Bairi et $\mathrm{al}^{19}$ also observed that most of their benign nodules were well defined with thin peripheral continuous halo.

Kim et $\mathrm{al}^{18}$ observed that of the 196 benign nodules, 97 were grade I, 44 were grade II, and 55 were grade III. Common US findings in the benign sponge-like nodules were ovoid to round shape $(n=194)$, smooth margins $(n=130)$, isoechogenicity $(n=178)$, and the presence of colloid microcrystals $(n=161)$.

Cytology: In the present study, on cytology a total of 115 cases (95.8\%) were diagnosed as benign lesions and 05 (4.1\%) were reported as malignancy.

Bairi et $\mathrm{l}^{19}$ too after cytological/histopathological evaluation, found that $6(8.57 \%)$ of the 70 nodules were malignant and 59 (91.43\%) were benign. 5 nodules, which were given as follicular neoplasms on FNAC, were diagnosed as follicular adenomas at histopathology. All the malignant nodules on FNAC were found to be papillary carcinomas.

Banstola et $\mathrm{al}^{21}$ in their study found that on cytological study, $70 \%$ cases were diagnosed as benign, $28 \%$ as malignant and $2 \%$ as inadequate for evaluation.

Chinta et $\mathrm{al}^{20}$ observed that out of 100 lesions, 68 (64 were benign and 4 were malignant) were hyper echoic, 27 (9 were benign and 18 were malignant) were hypoechoic and 3 were 
isoechoic and 2 were anechoic.

\section{CONCLUSION}

Lesions of the thyroid are common in the general population and middle-aged females are more often affected than males. Benign lesions outnumber the malignant lesions. Well defined margins, predominantly solid texture, absence of microcalcification, hyperechoiec and isoechoiec lesions, wider-than-taller lesions and presence of peripheral halo are pointers towards benign pathology. USG findings of thyroid correlate well with the cytopathological diagnosis.

\section{REFERENCES}

1. Harach HR, Franssila KO, Wasenius VM. Occult papillary carcinoma of the thyroid. A "normal" finding in Finland. A systematic autopsy study. Cancer. 1985;56(3):531-538.

2. Singer PA, Cooper DS, Daniels GH, Ladenson PW, Greenspan FS, Levy EG, et al. Treatment guidelines for patients with thyroid nodules and well-differentiated thyroid cancer. American Thyroid Association. Arch Intern Med. 1996;156(19):2165-2172.

3. Lyshchik A, Moses R, Barnes SL, Higashi T, Asato R, Miga MI, et al. Quantitative analysis of tumor vascularity in benign and malignant solid thyroid nodules. J Ultrasound Med. 2007;26(6):837-846.

4. Ezzat S, Sarti DA, Cain DR, Braunstein GD. Thyroid incidentalomas. Prevalence by palpation and ultrasonography. Arch Intern Med. 1994;154(16):18381840.

5. Tan GH, Gharib H. Thyroid incidentalomas: management approaches to nonpalpable nodules discovered incidentally on thyroid imaging. Ann Intern Med. 1997;126(3):226-231.

6. Ugurlu S, Caglar E, Yesim TE, Tanrikulu E, Can G, Kadioglu P. Evaluation of thyroid nodules in Turkish population. Intern Med. 2008;47(4):205-209.

7. Tabaqchali MA, Hanson JM, Johnson SJ, Wadehra V, Lennard TW, Proud G. Thyroid aspiration cytology in Newcastle: A six year cytology/ histology correlation study. Ann R Coll Surg Engl 2000;82(1):149-55.

8. Cooper DS, Doherty GM, Haugen BR, Kloos RT, Lee SL. American Thyroid Association (ATA) Guidelines Taskforce on Thyroid Nodules and Differentiated Thyroid Cancer. Revised American Thyroid Association management guidelines for patients with thyroid nodules and differentiated thyroid cancer. Thyroid 2009;19(4):1167-214.

9. Polyzos SA, Kita M, Avramidis A. Thyroid nodules - stepwise diagnosis and management. Hormones (Athens). 2007;6(4):101-9

10. Frates MC, Benson CB, Charboneau JW, Cibas ES, Clark OH, Coleman BG, et al. Management of thyroid nodules detected at US: Society of Radiologists in Ultrasound consensus conference statement. Radiology 2005;237(3):794-800.

11. Marqusee E, Benson CB, Frates MC, Doubilet PM, Larsen PR, Cibas ES, et al. Usefulness of ultrasonography in the management of nodular thyroid disease. Ann Intern Med. 2000;133(9):696-700.

12. Fujimoto Y, Oka A, Omoto R, Hirose M. Ultrasound scanning of the thyroid gland as a new diagnostic approach. Ultrasonics. 1967;5(1):177-80

13. Solbiati L, Charboneau JW, Osti V, James EM, Hay ID. The thyroid gland. In: Wilson SR, Charboneau JW, Rumack CM, editors. Diagnostic Ultrasound. $3^{\text {rd }}$ ed. Missouri: Mosby, Elsevier Inc.; 2005. p. 735-70.

14. Yeung MJ, Serpell JW. Management of the solitary thyroid nodule. Oncologist 2008;13(3):105-12.

15. Bruno A., Policeni Wendy, R.K Smoker, Deborah L. Reede. Anatomy and Embryology of the thyroid and parathyroid glands. Semin ultrasound CT MRI, 2012; 33(2): 104-114.

16. Khafagi F, Wright G, Castles H, Perry-Keene D, Mortimer R. Screening for thyroid malignancy: the role of fine needle aspiration biopsy. Med J Aust 1988; 149(4): 302-303, 306-307

17. Sharma G, Keshava GH,Hanchinal V.Ultrasonographic Evaluation of Thyroid Nodules with Pathologic Correlation. International Journal of Anatomy, Radiology and Surgery 2017;6(2): RO53-RO57.

18. Kim JY, Jung SL, Kim MK, Kim TJ, Byun JY. Differentiation of benign and malignant thyroid nodules based on the proportion of sponge-like areas on ultrasonography: imaging-pathologic correlation. Ultrasonography 2015;34(4): 304-311.

19. Bairi A, Ahmed N, Sreedevi T, Swapna Ch, Madhavi Latha R, Jagdeesh Babu. Role of Ultrasonography to Differentiate Benign and Malignant Thyroid Nodules in Correlation with Fine-needle Aspiration Cytology. Int J Sci Stud 2016;4(5):81-87.

20. Chinta VP. Evaluation of correlation between ultrasonography and FNAC of thyroid nodules. IAIM 2016;3(2):92-97.

21. Banstola L. Correlation of ultrasonography guided fine needle aspiration cytology of thyroid nodules with histopathology. Journal of Pathology of Nepal 2018;(1):1271- 275.

\section{Source of Support: Nil; Conflict of Interest: None}

Submitted: 12-09-2019; Accepted: 03-10-2019; Published online: 24-01-2020 